\title{
RESPONSABILIDADE CIVIL DO ESTADO POR ATOS JUDICIAIS NO BRASIL ${ }^{*}$
}

\author{
Daniele Maciel da Silva \\ Aluna do Curso de Graduação da Faculdade de \\ Direito de Universidade de São Paulo.
}

Resumo:

Desde a derrubado do regime absolutista, o Estado vem passando por significativas mudanças, uma vez a responsabilidade civil ser um instituto com influência de grandes idéias e correntes politicas do mundo c que refletem de modo sensivel o momento histórico universal.

Abstract:

Since the falling of the absolutist regimen, the State passes through significant changes, once the civil liability to be an institute with influcnce of great idcas and politics chains of the world and that they reflect in sensible way the universal historical moment.

Unitermos: Estado; responsabilidade civil: atos judiciais.

Keywords: State, civil liability, judicial acts.

Atuando como tutor dos interesses coletivos $\mathrm{e}$ interferindo incessantemente nas mais diversas esferas da vida pública, o Estado submete-se a determinados deveres para com a pupulação. Neste contexto insere-se a responsabilidade civil do Estado, que diz respeito à obrigação a este imposta de reparar danos causados aos administrados em decorrência de comportamentos comissivos ou omissivos, materiais ou jurídicos, lícitos ou ilícitos, imputáveis aos agentes públicos.'

A responsabilidade civil do Fstado é instituto cuja evolução, delineada pelos vários sistemas jurídicos. sofre direta influência das grandes idéias e correntes políticas do mundo, ultrapassando, por isso mesmo, as restritas colocações locais e

* O presente trabalho foi apresentado como parte do relatório do Programa Institucional de Iniciação Cientifica PIBIC/CNPq 2002/2003.

Agradeço sinceramente à Professora MARIA Syı via ZANElladi PIETRO, titular de Direito Administrativo, pela atenção e apoio dados para a publicação do presente estudo.

1. M. S. Di Pietro. Direito Administrativo. 14. ed. São Paulu: Editora Atlas. 2002. p.523. 
refletindo de modo sensivel o momento histórico universal. ${ }^{2}$ Tendo suas raízes na reação à arbitrariedade do Poder Público, o instituto sofreu significativas mudanças influenciadas diretamente pelas transformações por que vem passando o Estado desde a derrubada do regime absolutista.

O Estado Moderno se constitui e se desenvolve em virtude de uma série de integrações, sendo tal lenômeno acompanhado por uma crescente extensão do Direito do Estado aos diferentes círculos da atividade humana; ${ }^{3}$ e à proporção que se estendem os direitos estatais, multiplicam-se também, conseqüentemente, os seus deveres. Assim, partindo-se da idéia de uma completa irresponsabilidade civil do Poder Público. representado, então. pela figura do soberano. chegou-se, com a admissão da personalidade jurídica do Estado. ${ }^{4}$ à tese de sua responsabilidade objetiva, normatizada, pelo ordenamento pátrio, no $\S 6^{\circ}$ do art. 37 da Constituição Federal.

As teorias objetivas levam em conta. principalmente. o dano. a relação entre o fato ou ato da Administração e os efeitos produzidos, procurando o restabelecimento do valor econômico, reduzido pelo dano, sem se preocuparem com considerações de natureza subjetiva. humana, expressas no dolo ou na culpa do agente público ${ }^{5}$ Orienta-se a concepção da responsabilidade objetiva do Estado por dois princípios: a) da equidade. em virtude do qual o causador de prejuizo a outrem fica obrigado a reparar o dano: b) da igualdade de todos ante os ônus e encargos da Administração também denominado princípio da "solidariedade social"-, pois, se em tese todos se beneficiam das atividades da Administração, todos (representados pelo

2. J. CRETElla JúNIOR. O Estado e a obrigação de indenizar. Rio de Janeiro: Ruvista Forense, 1998. p. 175.

3. M. Renı E. Teoria do Direilo e do Estado. 5. ed., São Paulo: Editora Saraiva, 2000. p 217.

4. A formação c o grau de responsabilidade a seren imputados à Administração Pública são influenciados diretamente pela persunalidade juridica do Estado - W. Z. BRUNINI, Du responsabilidade extracontratual da administraçào pública, São Paulo, Ed. Revista dos Tribunais, 1981. p.20.

5. J. CRETELLA JÚNIOR. O Estado e a obrigação cit. (nota 2, supra). p. 180. 
Estado), devem compartilhar do ressarcimento dos danos que essas atividades causam a alguns. ${ }^{6}$

O Estado interfere na vida social através das funções desempenhadas por seus três Poderes: Executivo, Legislativo e Judiciário, devendo, portanto, responder objetivamente pelos danos advindos de suas atividades. Entretanto, verifica-se, que, de fato, a regra é aplicada apenas, em geral, com relação aos danos gerados por atos administrativos.

A coletivização dos conflitos, a ampliação do informalismo e da oralidade nos processos, a juridicização de questões antes entregues à livre deliberação política, completam um quadro geral de fatores que explicam porque a questão da responsabilidade do Poder Judiciário figura atualmente no centro da discussão pública. Neste contexto, deve-se questionar com maior intensidade a tradicional orientação dos tribunais, que toma a irresponsabilidade do Estado por danos decorrentes da prestação jurisdicional como regra e a responsabilidade como exceção. ${ }^{7}$

Sobre a irreparabilidade do prejuízo causado pelo ato judicial danoso repousa o último baluarte da teoria da irresponsabilidade civil do Estado. Apesar de rica elaboração doutrinária em sentido favorável. a responsabilização do Estado por danos oriundos de atos jurisdicionais ainda não encontra guarida no ordenamento pátrio. ${ }^{8}$ Merece menção, todavia, uma importante decisão do STF que pode significar mudança de orientação da jurisprudência no que diz respeito à matéria. ${ }^{9}$ Em decisão

6. O. Medauar. Direito administrativo moderno. 7. ed. São Paulo: Editora Revista dos Tribunais. p. 395 .

Assim como a igualdade dos direitos, também a igualdade dos encargos é hoje fundamental no Direito Constitucional dos povos civilizados. Portanto, dado que um indivíduo seja lesado nos seus direitos, como condição ou necessidade do bem comum, segue-se que os efeitos da lesão, ou os uncargos da sua reparação, devem ser igualmente repartidos por toda a coletividade, isto é, satisfeitos pelo Estado. a fim de que, por este modo, se restabeleça o equilibrio da justiça comutativa - A. CAVALC.ANTl, Responsabilidade civil do Estado, Rio de Janeiro, Laemmert \& C., 1905, p. XI.

7. P. MODESTO, Responsahilidade do Estado pela demora na prestação jurisdicional, in Revista de Direito Administrativo, v. 227, Rio de Janeiro, Fundação Getúlio Vargas. jan./mar. 2002. p. 307 e 308.

8. O. Medauar. Direito administrativo cit. (nota 6, supra), p. 402.

9. M. S. Di PIETRu. Direito Administrativo. 16. ed. São Paulo, Editora Atlas, 2004 p.535. 
assentada pela $2^{\mathrm{a}}$ Turma no julgamento do RE $228.977,{ }^{10}$ contra o entendimento do Tribunal de Justiça de São Paulo, acordaram os Ministros que: "A autoridade judiciária não tem responsabilidade civil pelos atos jurisdicionais praticados. Os magistrados enquadram-se na espécie agente politico, investidos para o exercício de atribuições constitucionais, sendo dotados de plena liberdade funcional no desempenho de suas funções, com prerrogativas próprias e legislação especifica"

Até então, a regra geral na matéria, segundo a jurisprudência majoritária, era a responsabilidade pessoal do magistrado, baseada em sua conduta culposa ou dolosa, nos termos dos arts. 133 do Código de Processo Civil e 49 da Lei Orgânica de Magistratura Nacional. ${ }^{11}$ Dispõe estes que: "Responderá por perdas e danos o juiz, quando: I- no exercicio de suas funções, procedeu com dolo ou fraude: II - recusar, omitir ou retardar, sem justo motivo, providência que deva ordenar de oficio, ou a requerimento da parte", ressalvando seu parágrafo único que: "Reputarse-ão verificadas as hipóteses previstas no $n$. II só depois que a parte, por intermédio do escrivão, requerer ao juiz que determine a providência e este não the atender o pedido dentro de dez (10) dias"

Apoiados nos argumentos da necessidade de preservação da independência do Judiciário, da autoridade da coisa julgada e da condição dos juízes

10. Publicado no DJU de 12-4-2002.

I I. “Ao Poder Judiciário, salvo casos expressamente previstos em lei, nào se aplica o princípio da responsabilidade objetiva do Estado, uma vez que a administração da Justiça é um dos privilégios da sobırania. Assim, a Administração não está obrigada a reparar o dano suportado por particular we o Juiz, ao julgar erroneamente a causa, não incorreu em dolo ou fraude" (RE 219.117-4 - PR - I ". T j.03.08.1999 - rel. Min. Ilmar Galvão - DJU 29.10.1999) - RT 772/152.

"Em não havendo prova da conduta dolosa ou fraudulenta do juiz, donde resulte dano, não há como responsabilizá-lo, nos termos do art. 133, do CPC e do art. 49, da Lei Orgânica de Magistratura Nacional. muito menos responde o Estado" (RE 111.609 - rel. Ministro Moreira Alves) RDA 193/316.

"Responsabilidade objetiva do Estado. Ato do Poder Judiciärio. A orientação que veio a predominar nesta Corte. em face das Constituiçõcs anteriores a de 1988, foi a de que a responsabilidade objetiva do Estado não se aplica aos atos do Poder Judiciário a não ser em casos expressamente declaradas em lei" (STF, RE $111.609 / \mathrm{AM}$, Rel. Min. Moreira Alves, ${ }^{a}$ T., unânime. j. 11.12/92) - RDA 227/292.

Outros julgados semelhantes: RD 13/542 e 22/527, e RDA vols. 53/183, 105/217 e 50/239. 
como órgãos da soberania nacional, ${ }^{12}$ os tribunais têm admitido a responsabilidade objetiva do Estado apenas em hipóteses expressamente indicadas em lei, sem que se faça distinção quanto a danos decorrentes de comportamentos ilícitos, comissivos ou omissivos do Estado-Juiz, ${ }^{13}$ que são as de erro judiciário em condenação penal e de prisão além do tempo fixado na sentença, elencadas no inciso LXXV, do art. $5^{\circ}$ da

12. De todo o esforço se dá conta que doutrina e jurisprudência se fixam no sentido da não responsabilidade civil do Estado pelos atos judiciais, salvo disposição legal expressa, em função dos seguintes princípios: 1) a responsabilidade civil do Estado disciplinada no art. $37, \S 6^{\circ}$, da Constituição de 1988 não compreende os danos resultantes da atividade judiciária, não se qualificando o juiz como funcionário ou agente do Estado; o Judiciário é um Poder que se exerce na prestação jurisdicional; 2) a sentença é um ato de soberania, nas mesmas condições em que o é o provimento emanado do Poder Legislativo; 3) a indıpendência do magistrado não permite que esteja ele exposto ao constrangimento de decidir em desacordo com a sua consciência, sob pena de ser demandado por esta ou aquela parte; 4) os efeitos da coisa julgada induzem a presunção de justiça da sentença; 5) eventuais erros do juiz no desempenho de sua atividade somente podem ser levados à conta da falibilidade humana, restando sua responsabilidade apenas em casos de dolo ou fraude - Y. S. CAHALI, Da responsabilidade cit. (nota 8. supra), p. 628.

“A responsabilidade do Estado por ato de seus Juizes só nasce quando ocorra erro judiciário ou as demais hipóteses previstas na Carta Magna, tais como a prisão indevida e a prisão além do tempo fixado na sentença. O erro judicial, in genere só assume relevância quando decorra de dolo ou culpa. Resulta dessas proposições que nem o Estado. nem o Magistrado respondem por error in judicando, ou seja, em razão do julgamento injuridico ou equivocado ou que venha a ser modificado pela instância superior" (El 078.31l-5/5-01 - 3². Câm. - j.24.04.2001 - rel. Dês. Rui Stoco) RT 790/245.

"Os atos estritamente inerentes à função jurisdicional, são insuscetiveis de proporcionar margem à responsabilidade civil do Estado, pelos possíveis danos que deles possam advir, pois o juiz na aplicação da lei desenvolve a própria missão da soberania do Estado. Quer dizer - dentro do seu convencimento, dinamiza o ordenamento juridico, assim como acontece com os membros do legislativo, as suas decisões e os seus feitos não podem gerar reparação, pois seria negar-se os principios que regem o Poder Judiciário" ( RE 111.609 - rel. Ministro Moreira Alves) - RDA 193/316.

"É sabido que as decisões judiciais não podem ensejar ressarcimentos por eventuais danos acarretados aos litigantes ou terceiros. É incontroverso em prol da coisa julgada, a liberdade dos magistrados, que não poderiam ficar à mercê de serem responsabilizados patrimonialınente pela indiscutida falibilidade humana de seus julgados. Todavia, o juiz é responsável por dolo, fraude, recusa, omissão ou retardamento injustificado de providências de sua função, conforme estatui o art. 133 do CPC, enquanto que essa responsabilidade não se transmite e nem obriga ao Estado" (TJRJ - AC 8084/96 - Reg. 040997 - Cód. 96.001.08084 - Capital - 8 C. Civ. - Rel. dês. Edil Pereira da Silva - J. 27.05.1997) - RDA 227/292.

13. P. MODESTO. Responsabilidade cit. (nota 7, supra), p. 292 e 293. 
Constituição Federal ${ }^{14}$ Verificando-se o primeiro caso, estabelece o $\S 2^{\circ}$ do art. 630 do Código de Processo Penal que: "A indenização não será devida: a) se o erro ou a injustiça da condenação procede de ato ou falha imputável uo próprio impetrunte, como a confissão ou a ocultação de prova em seu poder; b) se a acusação houver sido meramente privada" Circunstância esta que não possui o menor fundamento constitucional, pois não é o fato de a acusação ter sido privada que tirará o caráter do ato de jurisdicional, do Poder Judiciário a condição de Estado no exercício de função que lhe é própria, nem do juiz a qualificação de agente público no exercício de suas funções. ${ }^{15}$ Têm os tribunais entendido que, também com relação a atos judiciais que não impliquem exercício de função jurisdicional, é cabivel a responsabilidade do Fstado, sem maior contestação, porque se trata, quanto ao seu conteúdo, de atos administrativos. $^{10}$ Os atos administrativos são aqueles decorrentes da execução, estruturação ou administração dos serviços próprios do Poder Judiciário. ${ }^{17}$ tais como nomeações; compras; transportes; determinação de correção em cartórios; concessão

14. Art. $5^{\circ}$, LXX da CF: "O Estado indenizará o condenado por erro judiciário, assim como o que ficar preso além do tempo fixado na sentença"

O texto constitucional, assegurando a reparação à vitima do erro judiciário, não condiciona o exercicio da pretensão indenizatória ao prévio acolhimento de revisão da sentença condenatória - Y.S. CAHALI, Responsabilidade civil cit. (nota 8, supra). p. 603.

15. E. NETTO DE ARAúuo. Responsabilidade do Estado por aıo jurisdicional. São Paulo: Editora Revista dos Tribunais, 1981.p.113.

Comentando o inciso II do $\S 2^{\circ}$, do art. 630, C.AHAl I afirma que "ocorrendo enro judiciánio na açāo penal em que "a acusação houver sido meramente privada", se já então discutivel a excludente de responsabilidade do Estado pela indenização em face do art. $630, \S 2^{\circ}$, do Código de Processo penal, essa ressalva já não mais prevalece diante da literalidade do art. $5^{\circ}$, LXXV, da Constituição de 1988 , que não estabelece nenhuma distinção entre os processos criminais em que terá falhado a máquina judiciária na prestação jurisdicional Y.S. CAHAL, Da responsabilidade cit. (nota 8, supra), p. 609.

I6. M. S. Z. DI PIE TRO. Direito cil. (nota I, supru), p. 535.

"Somente o ato de caráter judicial, e não puramente administrativo, como seja o limite imposto a provisão concedida para advogar pelo Presidente do Tribunal, é que isenta o Estado da responsabilidade civil" (STF - Ac de 18.9.1940) - RT 135/749.

"Quando o ato é dos que se compreendem no exercício da jurisdição graciosa ou administrativa, sem a roupagem da res judiciala, nada impede que se chame a contas o Poder Público, quando seu representante (a auturidade judiciária) exorbite de suas funções. abuse de seu poder. proceda contra 0 direito, ou falta a dever prescrito em Ici" (TJSP - Ac. De 18.9.1941) - RT 135/680

17. E. Netto de ARaúJo. Responsabilidade do Estado cit. (nota 14, supra), p. 87. 
de férias, licenças, aplicação de sanções e exercício de poderes concernentes à polícia administrativa feitos pelo Presidente do Tribunal de Justiça. ${ }^{18}$ Todavia, não se pode permitir o reconhecimento da responsabilidade civil do Estado apenas quando o crro verificado resulta de ato judicial em sede de jurisdição administrativa ou correcional, a se pretender excluir a responsabilidade quando resultante o erro judiciário do exercício de prestação jurisdicional típica através de sentença, no pressuposto de sua imutabilidade, decorrente da formação de coisa julgada. ${ }^{19}$

Poucos foram os julgados que admitiram a responsabilidade do Estado pela prática de atos judiciais danosos fora das hipóteses acima citadas, ${ }^{20}$ sendo múltiplas as críticas a esta posição predominante nos tribunais, estendendo-se seu objeto desde os problemas relativos à aplicabilidade da regra contida no art. 133 do Código de Processo Civil às questões referentes à responsabilidade pública ${ }^{21}$ até a amplitude da expressão "erro judiciário" Uma das objeções que se faz à responsabilização pessoal do magistrado é o fato desta ser considerada fator gerador de sérios problemas ao sistema jurídico, tais como: a) a entrega do juiz a demandas diretas das partes, fato que, ao revés de preservar a sua autonomia, desestabiliza c inquieta a ordem normativa, tendo levado vários países - como Alemanha. Áustria,

18. J.CRETELLA JÚNIOR. O Estado c a obrigaçâo cit. (nota 2, supra), p. 241.

19. Y. S. CAHALI, Da responsabilidade cit. (nota 8, supra), p. 645.

20. São eles: a) "Ação criminal privada. Demora no seu andamento. A atividade jurisdicional do Estado, manifestação de sua soberania, só pode gerar responsabilidade civil quando efetuada com culpa, em detrimento dos preceitos legais reguladores da sspécie" (STF, RE n. 32.518-RS, j. 21.6.66) - RF 220/105 - este julgado, embora não tenha admitido a responsabilidade objetiva do Estado por ato ou omissão na prestação jurisdicional, reconheceu-a quando se pudesse provar dolo ou culpa. ainda que anônima. do serviço P. MODESTo, Responsabilidade do Estado pela demora na prestação jurisdicional, p. 298, nota 9; b) "Ação de indenização contra o Estado em razão de dano irreversível causado à parte por virtude de omissão ilegal verificada em ato jurisdicional. Inteligência do art. $37, \S 6^{\circ}$, da Cl de 1988" (TJRJ - Ap. Civ. $4154 / 90$ - Ac da 4 a Câmara Cível em 27.08.1991 - Rel. Des. Antônio de Castro Assumpção, in Adcoas Jurisprudência, 1992, n. 136.0I1) - P. MODESTO, Responsabilidade cit. (nuta 7, supra), p. 298. nota 9; c) "Responsabilidade civil da União por decisão judicial. Inexistência de causa fática a determinar. A responsabilidade civil do Estado pela prática de ato judicial só ocorre quando há demonstração inequivoca de que o dano produzido decorreu de decisão teratológica, e foi provocado por vontade dolosa do julgador ou decorrente de mau funcionamento do serviço ou omiscão de praticar fatos a que o poder público estava obrigado" (TRF 5, DJ 27.9.93 - Rel. Juiz José Delgado) P MODESTO, Responsabilidade cit. (nota 7, supra), p. 298, nota 9.

21. O artigo 133 do CPC em nada interfere na responsabilidade civil do Estado pelos atos de seus agentes, cuidando especificamente da responsabilidade pessoal do juiz em razão da prestação jurisdicional a seu cargo - Y. S. CAHALI, Responsabilidade civil cit. (nota 8, supra), p. 628. 
Polônia e França a adotarem a tese da responsabilidade do Estado; b) a fácil conversão em irresponsabilidade, dada a dificuldade de demonstração de culpa pessoal do magistrado. ${ }^{22}$

Outro ponto ressaltado repousa no fato de se considerar o erro judiciário como sinônimo de sentença criminal de condenação injusta, quando aquele, por extensão, abrange também a prisão preventiva injustificada ou detenção, sem justa causa, cujos danos patrimoniais e morais são patentes. ${ }^{23}$ Com efeito, não se compreende que, sendo injusta a prisão no que exceder o prazo fixado na sentença condenatória, seja menos injusta a prisão do réu que nela é mantido se ao final vem a ser julgada improcedente a denúncia pela sentença absolutória. ${ }^{24}$ Interpretar o erro judiciário apenas no âmbito penal, todavia, é evidentemente, uma conduta demasiado simplista, pois este pode abranger também o erro no processo civil, trabalhista. eleitoral ou em qualquer outra área de atuação jurisdicional; pode ser erro in procedendo ou in judicando; pode decorrer de erro, dolo ou culpa (negligência, imperícia ou imprudência). ${ }^{25}$ O que se entende por erro judiciário é a sentença equivocada, quer seja emitida $\mathrm{em}$ um processo criminal, quer tenha origem $\mathrm{cm} \mathrm{um}$ procedimento não penal. ${ }^{26}$

A responsabilidade estatal sofre grandes prejuizos em detrimento da falsa idéia de intangibilidade, inacessibilidade e infalibilidade que recai sobre a figura do magistrado. ${ }^{27}$ Prejuizos estes intensificados pela crença em que a soberania do

22. P. MODESTO. Responsabilidade do Estado cit. (nota 7, supra), p. 295.

23. J. CRETElla JÚNIOR. O Estado e a obrigação cit. (nota 2, supra), p. 253.

Neste mesmo sentido, AGUIAR DIAS assim se pronuncia: "Danos e tragédias decorrem, por igual, de uma e de outros. Onde existe a mesma razão, deve valer a mesma disposição" A. DIAS, Da Responsabilidade civil. 1. .Il, 10. ed., Rio de Janeiro, Revista Forense, 1997, p. 637.

24. Y. S. CAHALI. Responsabilidade civil cit. (nota 8, supra), p. 603. Para o autor impõe-se no listado de Direito o reforço da garantia dos direitos individuais dos cidadãos. devendo ser coibida a prática de qualquer restrição injusta à liberdade individual, decorrente de ato tão abusivo da autoridade judiciária, e se fazendo resultar dela a responsabilidade do Estado pelos danos causados (p. 602).

25. M. S. Z. Di PIETRO. Responsahilidade do Estado por alos jurisdicionais, in Revistade Dineito Administrativo, v. 198, Rio de janeiro, Fundação Getúlio Vargas, p. 90 e 91.

26. E. NETTO DE ARAújo, Responsabilidade do Estado cit. (nota 14. supra), p. 113.

27. M. S. Z. DI PIETRO. Direito cit. (nota 1, supra), p. 535.

Erro este atribuído às garantias de que se cerca a magistratura no Direito brasileiro, previstas para assegurar a independência do Poder Judiciário e que não se estendem aos demais agentes públicos, gerando o efeito oposto de liberar o Estado de responsabilidade pelos danos injustos causados àqueles que procuram o Poder Judiciário precisamente para que seja feita justiça. 
Poder Judiciário é uma excludente da responsabilidade patrimonial do Poder Públicn por atos judiciais, quando de fato não existe autonomia entre sobcrania e responsabilidade, como não há relativamente ao Poder Executivo, ${ }^{28}$ cujos atos danosos têm sua responsabilidade reconhecida pelos tribunais. A independência do Judiciário é outro argumento que não explica a imunidade estatal, visto que não há oposição entre ela e a responsabilidade do Estado, a qual não atinge a independência funcional dos juízes. ${ }^{29}$ além de ser atributo inerente a cada um dos Poderes estatais. ${ }^{30}$

$\Lambda$ ofensa à coisa julgada, apesar de ser o mais forte dos argumentos, também não justifica a irresponsabilidade pública pela prática de atos judiciais danosos. Além de sofrer restrições no Direito brasileiro na medida em que se admite a ação rescisória e a revisão criminal, o fato de ser o Estado condenado a pagar indenização decorrente de dano ocasionado por ato judicial não implica mudança na decisão judicial, que continuará valendo para ambas as partes. cabendo ao Estado responder pelo prejuizo que a decisão imutável ocasionou a uma das partes em decorrência de erro judiciário. ${ }^{31}$

Muitas ainda são as formas pelas quais pode ocurrer a chamada denegação da justiça por parte dos magistrados, ${ }^{32}$ fato que torna o não reconhecimento da responsabilidade estatal por ação ou omissão na prestação jurisdicional um dos pontos mais polêmicos sobre o assunto. A denegação da justiça

28. J. SEnto SÉ citado por AgUiar Dias, Responsabilidade cir. (nota 23.1.2, supra), p. 043.

29. J. SENTO SÉ, citado por AGUIAR DIAS, Responsabilidade cit. (nota 23.I.2, supra), p. 643.

30. M. S. Z. Di PIETRO. Direito cit. (nota 1, supra), p. 534.

31. M. S. Z. DI PIETRO. Direito cit. (nota 1, supra), p. 534.

A autora complementa a crítica afirmando que a própria presunção de verdade anibuída às decisões judiciais aparece enfraquecida num sistema judiciário como o nosso, em que o precedente judiciário não tem força vinculante para os magistrados; sendo comuns decisões contrárias e definitivas a réspeito da mesma norma legal, e uma delas. certamente. afronta a lei (p. 534 e 535).

CRETELLA JỨNIOR assim se manifesta: "Não militam a favor da irresponsabilidade do Listado, por atos judiciais, nem o argumento da soberania, nem o da incontrastabilidade da coisa julgada, em primeiro lugar porque soberano é o Estado, em segundo lugar porque a coisa julgada pode ser atacada no civel pela rescisória, ou pela revisão no crime" - J.CRETELLA JúNIOR, O Estado e a obrigação cit. (nota 2. supra), p. 260.

32. Seja: a) pela omissão em sentenciar, sob fundamento de lacuna da lei, com ofensa ao art. 126 do CPC; b) recusa, omissão ou retardamento, sem justo motivo, de providência que deva ordenar de oficio ou a requerimento da parte, conforme previsto no ant. $133 \mathrm{do}$ CPC; c) negligência em dar andamento ao processo; d) adiamento do julgamento para aguardar decisão de outro juiz; e) absolvição com base no princípio do indubio pro reo, quando a dúvida envolve apenas matéria de direito - M.S. ZANELLAD1 Pietro, Responsabilidadi do Estado cit. (nota 22, supra), p. 93 e 94. 
constitui uma das mais graves atividades danosas praticadas pelo magistrado, pois deixa sem contrapartida o direito constitucionalmente previsto de obter, pela via da ação judicial, a proteção aos direitos lesados ou ameaçados, não havendo, assim, como negar a responsabilidade do Estado c do juiz pelos danos decorrentes dessa lesão. ${ }^{33}$ A demora desarrazoada ou excessiva do processo traduz omissão antijurídica, violadora do dever de celeridade e eficácia que deve cercar a atividade processual administrativa e judicial. ${ }^{34}$

A responsabilidade do Estado por atos judiciais é espécie do gênero responsabilidade do Estado por atos decorrentes do serviço público, porque o ato judicial é, antes de tudo, ato jurídico público, ato de pessoa que exerce serviço público judiciário. ${ }^{35} \mathrm{O}$ STF. contudo entende não-caber a responsabilidade civil do Estado por falta do serviço em caso de decisão judicial, quando a demora tem causa justificada. ${ }^{36}$

Cahali, fazendo suas as palavras de Bielsa, atenta para o caráter político e jurídico-político que tem a responsabilidade pelo erro dos juízes, pois no Estado de Direito, as garantias jurisdicionais do indivíduo têm uma extensão considerável. Proporcional ao grau do progresso jurídico do Estado, em um sistema integral de justiça, o Estado não deve deixar sem reparação os sacrifícios individuais injustamente suportados; se, em princípio, o Estado não-responde por seus atos jurisdicionais (no sentido juridico próprio do conceito de responsabilidade), deve ele garantir a integridade da Justiça que administra. ${ }^{37}$

Não se pode esquecer ainda que no contexto da atividade nãojurisdicional dos órgãos vinculados ao Poder Judiciário insere-se a atividade do Ministério Público. E seus membros, atuando, dentro de sua especialização, como servidores públicos, no desempenho dos misteres que lhes são cometidos, podem, no exercício da função, provocar danos a terceiros determinantes de responsabilidade indenizatória do Estado. ${ }^{38}$

33. P MODESTO. Responsabilidade do Estado cit. (nota 7. supra).p. 94.

34. P. MODESTO. Responsabilidade do Estado cit. (nota 7. supra),p. 299.

35. J.CRETELla JÚNIOR. O Estado e a obrigação cit. (nota 2, supra), p. 259.

Neste mesmo sentido EDMIR NETTO DE ARAÚJO - Responsabilidade do Estado cit. (nota I4, sipra). p. 94.

36. RDA 90/140.

37. Y. S. CAHALI. Responsabilidade civil cit. (nota 8, supra), p. 628.

38 Y. S. CAHALI. Responsabilidad' civil cit. (nota 8. supra), p. 645 e 648. 
O progressivo reconhecimento da relevância do tema da responsabilidade civil do Estado traduz-se no recente Anteprojeto de Lei presidido por Caio Tácito. ${ }^{39}$ Trata este da responsabilidade civil do Estado quanto ao exercício da função jurisdicional e das funções institucionais do Ministério Público em seus arts. $18,19,20$ e $21,^{40} \mathrm{e}$, apesar de pouco inovar em relação à postura já adotada pelos tribunais, a iniciativa deste Anteprojeto representa a necessidade da existência de uma norma jurídica específica que regule a matéria.

A imposição de limites à responsabilização pública no Direito brasileiro é matéria que deve ser analisada de maneira bastante cuidadosa, pois apresenta consideráveis pontos antagônicos. Se por um lado é certo que o Estado não deve responder indiscriminadamente em hipóteses nas quais não contribuiu de qualquer modo para o advento do dano; por outro, não se pode negligenciar o fato de que sua atuação tem como pressuposto a proteção e o respeito aos direitos da coletividade. tornando inadmissível sua irresponsabilidade nos casos em que esta sirva como instrumento de perpetuação de injustiças e de violação dos princípios fundamentais do Direito. Insere-se nesta hipótese a regra da irresponsabilidade estatal pela prática de atos legislativos e judiciais danosos a terceiros.

A interferência estatal na vida social através das funções desempenhadas por seus três Poderes são de suma importância. Tanto assim que os poderes atribuídos à Administração têm o caráter de poder-dever. ou seja, são poderes que ela não pode deixar de exercer sob pena de responder pela omissão. ${ }^{41} \mathrm{O}$ que se

39. Texto publicado na RDA 229/369.

40. Art. 18. O Estado indenizará o condenado por erro judiciário e aquele que ficar preso além do tempo fixado na sentença.

Parágrafo único - A indenização não será devida, se o erro ou a injustiça da condenação decorrer de ato ou falta imputável ao próprio decorrer de ato ou falta imputável ao próprio interessado, como a confissão ou a ocultação de prova em seu poder.

Art. 19. O Estado responde pelos danos causados por dolo ou fraude do julgador, sem prejuizo do direito de regresso.

Parágrafo único - Enquanto não se esgotarem previamente os recursos previstos no ordenamento processual, descabe a caracterização de dano oriundo da função jurisdicional.

Art. 20. As disposições desta Lei aplicam-se aos órgãos do Ministério Público, quando no desempenho de função administrativa.

Art. 21. Sem prejuízo do direito de regresso, responde o Estado pelos danos decorrentes do exercício. pelo Ministério Público, de suas funções institucionais, quando os seus membros procederem com dolo ou fraude, ou fizerem uso indevido das informações e documentos que obtiverem, inclusive nas hipóteses legais de sigilo.

41. M. S. Z. Di Piftro. Direito cit. (nota 1, supra), p. 70. 
verifica, no entanto, no que tange à irresponsabilidade estatal referente aos atos judiciais, é que, além de não cumprir com seu dever, prejudicando a sociedade de modo geral, a omissão administrativa justifica-se pela imunidade atribuída aos agentes que atuam representando, direta ou indiretamente, estes Poderes.

Os efeitos da aplicação do instituto jurídico da responsabilidade civil do Estado incidem duplamente sobre a vida pública, pois garantem ao indivíduo o ressarcimento do prejuizo sofrido e à sociedade, a punição daqueles que a desrespeitam, seja agindo dolosa ou indiferentemente. Assim, um dos principais aspectos da responsabilidade estatal, e que freqüentemente é ignorado nas discussões sobre a matéria, consiste na maior vigilância que recai sobre os representantes do Estado, ${ }^{42}$ ou seja, em sua própria razão de ser, qual seja, o controle do poder.

Vigilância esta cujas proporções nos campos legislativo e judiciário são absolutamente essenciais para a construção de uma sociedade mais justa. Sobre as funções legislativas e judiciais é que se apóiam as relações sociais e a própria existência do Poder Público. Desta forma, os agentes que exercem estas atividades devem ter plena consciência da essencialidade de seu dever para com a Nação, e não se aproveitar do cargo que ocupam para obter privilégios individuais em detrimento do desrespeito aos princípios éticos e morais que devem orientar suas condutas.

As limitações da responsabilidade civil do Estado, referentes aos atos legislativos e judiciais, simbolizam o conservadorismo, o anacronismo e a desigualdade, que, em muitos aspectos, ainda caracterizam o Direito pátrio e representam vergonhosa violação dos direitos constitucionais. A indiferença com que o Poder Público tutela os interesses coletivos é digna de revolta não-só por configurar inaceitável desrespeito aos cidadãos brasileiros, infringindo o princípio da igualdade e as garantias individuais como, também, por consistir, ao violar o princípio da legalidade, em reiterada negação do próprio Direito que o legitima.

São Paulo. janeiro de 2004.

42. "Considerando que os atos materiais, pelos quais se manifesta a vontade do Estado, se praticam por intermédio de seus órgãos e funcionários, conclui-se que, na responsabilidade civil do Estado, se encontra, muitas vezes, a responsabilidade de seus agentes, quando ocorre dolo ou culpa. Relativamente ao funcionário, a palavra responsabilidade, no âmbito do Direito Administrativo, tem sentido tríplice, sendo, pois. necessário acompanhá-la de um atributo (civil, criminal. disciplinar), para especificar um desses casos" - J. CRETElla JúNIOR, Curso de Direito Administrativo, 16. ed., Rio de Janeiro, Revista Forense, 1999, p.78. 
Bibliografia

ARAUjO, Edmir Netto de. Responsabilidade do Estado por ato jurisdicional. São Paulo: Revista dos Tribunais, 1981.

BRUNINI, Weida Zancaner. Da responsabilidade extracontratual da administração pública. São Paulo: Revista dos Tribunais, 1981.

CAHALI, Yussef Said. Responsabilidade civil do Estado. 2. ed. São Paulo: Malheiros Editores, 1996.

CAVALCANTI, Amaro. Respunsubilidade civil de Estado. Rio de Janeiro: Laemmert \& $\mathrm{C}, 1905$.

CRETELLA JúnIOR, José. O Estado e a obrigação de indenizar. Rio de Janeiro: Revista Forense, 1998.

. Curso de Direito Administrativo. 16. ed. Rio de Janeiro: Revista Forense. 1999.

DI PIETRO, Maria Sylvia, Direito Administrativo. 14. ed. São Paulo: Editora Atlas, 2002.

. Direito Administrativo. 16. ed. São Paulo: Editora Atlas. 2004.

Responsabilidade do Estado por atos jurisdicionais. Revista de direito administrativo, Rio de Janeiro, v. 198.

DIAS, José de Aguiar. Da responsahilidade civil. 10. ed. Rio de Janeiro: Revista Forense, 1997. v. 2.

MEDAUAR, Odete. Direito administrativo Moderno. 7. ed. São Paulo: Editora Revista dos Tribunais, 2003.

MODESTO, Paulo. Responsabilidade do Estado pela demora na prestação jurisdicional. Revista de Direito Administrativo, Rio de Janeiro, v. 227, jan./mar. 2002.

REALE, Miguel. Teoria do Direito e do Esıado. 5. ed. São Paulo: Saraiva, 2000. 